\title{
Vitamin E Protects Against Hepatocyte Ultrastructural Damage Induced by High Fat Diet in a Rat Model of Pre-Diabetes
}

\author{
La Vitamina E Protege contra el Daño Ultraestructural de los Hepatocitos Inducido \\ por la Dieta Alta en Grasas en un Modelo de Pre-diabetes en Ratas
}

\author{
Mohamed Abd Ellatif ${ }^{1,5}$; Abbas O El Karib²; Mohammad Dallak²; \\ Refaat A Eid ${ }^{3}$; Rihab Al-Ani ${ }^{4} \&$ Mohamed A Haidara ${ }^{2,6}$
}

ELlATIF, M. A.; EL KARIB, A. O; DALLAK, M.; EID, R. A.; AL-ANI, R. \& HAIDARA, M. A. Vitamin E protects against hepatocyte ultrastructural damageinduced by high fat diet in a rat model of pre-diabetes. Int. J. Morphol., 36(4):1350-1355, 2018.

SUMMARY: We sought to investigate the potential protective effect of Vitamin E supplementation against hepatocyte ultrastructural alterations induced by high fat diet (HFD) in a rat model of pre-diabetes. Therefore, rats were either fed with HFD (model group) or a standard laboratory chow (control group) for 12 weeks before being sacrificed. The protective group fed on a HFD and started the treatment with vitamin E (100 mg/kg/day, i.p) from day 1 until being sacrificed at week 12 . The harvested liver tissues were examined using transmission electron microscopy (TEM) and blood samples were assayed for biomarkers of liver injury and prediabetes. TEM images showed that HFD induced profound pathological changes to the hepatocyte ultrastructure as demonstrated by degenerated hepatocytes with damaged cytoplasm that have mitochondrial swelling, dilation of endoplasmic reticulum, blebbing of plasma membranes, and cytoplasmic accumulations of lipid droplets and vacuoles, which were substantially but not completely protected with vitamin E. In addition, HFD significantly $(\mathrm{p}<0.05)$ augmented biomarkers of liver injury and pre-diabetes such as alanine aminotransferase (ALT), aspartate aminotransferase (AST), tumor necrosis factor-alpha (TNF- $\alpha$ ), malondialdehyde (MDA), total cholesterol (TC), triglycerides (TG), and low density lipoprotein cholesterol (LDL-C), which were significantly $(\mathrm{p}<0.05)$ reduced with vitamin E except TNF- $\alpha$ and TC. Furthermore, none of these biomarkers were reduced to the control level by vitamin E. We conclude that vitamin $\mathrm{E}$ is a partial protective agent against HFD-induced liver injury and pre-diabetes.

KEY WORDS: Hepatocyte ultrastructure; Pre-diabetes; Hepatic steatosis; Vitamin E; Animal model.

\section{INTRODUCTION}

The rapid rise in obesity, particularly among children in industrial and wealthy countries is a major public health problem and it is estimated that there are 35 million obesityrelated deaths worldwide per year (Lustig et al., 2012). Abdominal obesity is a criteria of the metabolic syndrome, also called pre-diabetes, which is a cluster of abnormalities characterized by insulin resistance, inflammation, oxidative stress, hypertension and dyslipidaemia which carries increased risk of type 2 diabetes mellitus(T2DM), cardiovascular disease, non-alcoholic fatty liver disease (NAFLD) and cancer (Kopelman, 2000; Eckel et al., 2005; Grattagliano et al., 2008). NAFLD is the hepatic component of pre-diabetes (Paschos \& Paletas, 2009) that affects liver function due to fat accumulation (hepatic steatosis) caused by dysfunction of fat metabolism in the liver (Benlhabib et al., 2004), which can lead to, if not treated, more serious complications such as nonalcoholic steatohepatitis (NASH), fibrosis, cirrhosis, liver failure and even hepatocellular carcinoma (Choi \& Diehl, 2005; Paschos \& Paletas). NAFLD is becoming the most common cause of liver disease in Western countries (de Alwis \& Day, 2008), and is associated with significant liver related morbidity and mortality (Byrne \& Targher, 2015).

The precise mechanisms of NAFLD are still not fully understood and there is no specific medicine to cure the

\footnotetext{
${ }^{1}$ Department of Clinical Biochemistry College of Medicine, King Khalid University, Saudi Arabia.

${ }^{2}$ Department of Physiology College of Medicine, King Khalid University, Saudi Arabia.

${ }^{3}$ Department of Pathology College of Medicine, King Khalid University, Saudi Arabia.

${ }^{4}$ Department of Microbiology College of Medicine, King Khalid University, Saudi Arabia.

${ }^{5}$ Department of Medical Biochemistry, Faculty of Medicine, Mansoura University, Mansoura, Egypt.

${ }^{6}$ Department of Physiology, Kasr al-Aini Faculty of Medicine, Cairo University, Cairo, Egypt.

This work was supported by King Khalid University grant number KKU-Project No. R.G.P.1/27/38.
} 
disease (Angulo \& Lindor, 2002), which left patients with only one option of effective treatment, liver transplant, if progress of the disease leads to a liver failure (Said, 2013; Zezos \& Renner, 2014). Therefore, treatment strategies for NAFLD aim to improve insulin sensitivity, decrease hepatic accumulation of fat, modify metabolic risk factors and protect the liver from oxidative stress (Chalasani et al., 2012). Vitamin $\mathrm{E}$ is an antioxidant that is wildly used in medicine and in cosmetic industry to protect the body and the skin from oxidative stress-induced deleterious effects (Brockes et al., 2003; Lee et al., 2013). Therefore, the aim of the present study was to investigate the protective effects of vitamin $\mathrm{E}$ on pre-diabetes-induced liver injury using TEM and blood chemistry.

\section{MATERIAL AND METHOD}

Animals. All experimental procedures were approved by the medical research ethical committee at King Khalid University and according to the Guide for the Care and Use of Laboratory Animals published by the US National Institutes of Health. (NIH publication No. 85-23, revised 1996). Sprague-Dawley rats $(n=24)$ weighing 170 $200 \mathrm{~g}$ were used in this study. All rats were bred and housed in the research center of King Khalid University, college of medicine (Abha, Saudi Arabia), at temperature of $23 \pm$ $1{ }^{\circ} \mathrm{C}$ and a $12 \mathrm{~h}$ light: $12 \mathrm{~h}$ dark cycle. Rats had free access to tap water and fed standard laboratory chow during the acclimatization period.

Experimental design. After a one week adaptation, the rats were randomly divided into four groups ( $n=6$ rats each). Animals in group 1 (Control) were used as the control group and fed with standard laboratory chow for 12 weeks. Animals in group 2 (Control+Vit E) were fed a standard laboratory chow for 12 weeks and were given vitamin $\mathrm{E}$ supplementation $(100 \mathrm{mg} / \mathrm{kg} /$ day, i.p.) from day 1 till the end of the experiment at weeks 12 . The third group was fed a HFD for 12 weeks. Animals in the fourth group (HFD+Vit E) were fed with HFD for 12 weeks and were given vitamin E supplementation (100 mg/kg/day, i.p.) from day 1 till the end of the experiment at weeks 12 .

\section{Biochemical measurements}

Blood samples. At the end of experimental period, blood samples were collected by cardiac puncture under anesthesia ( sodium thiopentone at $40 \mathrm{mg} / \mathrm{kg}$ body weight ) after an overnight fast of $12 \mathrm{~h}$. These blood samples were collected without anticoagulant, left for $10 \mathrm{~min}$, then centrifuged for $10 \mathrm{~min}$ at $4000 \mathrm{r} / \mathrm{min}$ to obtain serum, which was stored at $-20{ }^{\circ} \mathrm{C}$ until further biochemical analysis for determination of serum liver enzymes, oxidative stress and inflammatory biomarkers, and lipids.

\section{Determination of serum levels of ALT, AST, and TNF- $\alpha$.} After 12 weeks, animals were sacrificed and liver function was evaluated by assessing serum ALT and AST levels using an enzymatic kit (Randox Laboratories, Crumlin, UK) according to the manufacturer's instructions. Serum levels of TNF-a, (ELISA kit BIOTANG INC, Cat. No. R6365, MA, USA) was used as recommended by the manufacturer.

Determination of MDA, measured as Thiobarbituric acid reactive substances (TBARS) in liver homogenate. TBARS in liver tissues were analyzed as previously mentioned (Ohkawa et al., 1979). Sections of liver were placed in a total volume of $3 \mathrm{ml}$ cold $100 \mathrm{mM} \mathrm{KCl}$ plus $0.003 \mathrm{M}$ EDTA and homogenized. Homogenates were centrifuged at $600 \mathrm{~g}$ for $15 \mathrm{~min}$. Then, $0.4 \mathrm{ml}$ of supernatant were added to $0.2 \mathrm{ml} \mathrm{8.1 \%} \mathrm{SDS,} 1.5 \mathrm{ml} 20 \%$ acetic acid (pH 3.5), $1.5 \mathrm{ml} 0.8 \%$ thiobarbituric acid, and $0.6 \mathrm{ml}$ water. This solution was heated to $95^{\circ} \mathrm{C}$ for $60 \mathrm{~min}$. After addition of $1.0 \mathrm{ml}$ water and $5.0 \mathrm{ml}$ of $\mathrm{n}$-butanol-pyridine mixture $(15: 1, \mathrm{vol} / \mathrm{vol})$, the mixture was vigorously shaken and centrifuged at $2,000 \mathrm{~g}$ for $15 \mathrm{~min}$. The absorbance of the upper layer was read at $532 \mathrm{~nm}$ (Shimatzu model UV21100S spectrophotometer, Kyoto, Japan). Standard TBARS (Sigma, UK) was used as the external standard. Results are expressed as $\mathrm{mM} / 100$ gof tissue.

Determination of serum levels of triglyceride, cholesterol, high density lipoprotein, and low density lipoprotein. After 12 weeks, animals were sacrificed and serum levels of triglycerides (TG), total cholesterol (TC), high density lipoprotein cholesterol (HDL-C), and low density lipoprotein cholesterol (LDL-C) were measured using commercial kits supplied by SPINREACT, Spain, according to the manufacturer's instructions.

Transmission Electron Microscopy (TEM). Small pieces of liver tissues were removed and immediately fixed in 2.5 $\%$ glutaraldehyde for $24 \mathrm{~h}$, and washed with phosphate buffer (0.1 M, PH 7.4). Post fixation was made in $1 \%$ osmium tetroxide buffered to $\mathrm{PH} 7.4$ with $0.1 \mathrm{M}$ phosphate buffer at $4{ }^{\circ} \mathrm{C}$ for $1-2 \mathrm{~h}$. The samples washed in phosphate buffer to remove excess fixative, dehydrated through ascending grades of ethanol followed by clearing in propylene oxide. The specimens were embedded in Araldite 502, to form gelatin capsules. Polymerization was obtained by placing the capsules at $60{ }^{\circ} \mathrm{C}$. Semi-thin sections $(\sim 1 \mathrm{~mm}$ thick) were stained with toluidine blue for orientation and observation. Ultra-thin sections $(100 \mathrm{~nm})$ were prepared using ultramicrotome and picked up on uncoated copper grids. 
Following double staining with uranylacetate and lead citrate, three to five random micrographs for each section were examined and photographed using a JEM-1011JEOL transmission electron microscope, Japan, at $80 \mathrm{Kv}$.

Statistical analysis. The data was expressed as mean \pm standard deviation (SD). Data was processed and analyzed using the SPSS version 10.0 (SPSS, Inc., Chicago, Ill., USA). Oneway ANOVA was done followed by Tukey's post hoc test. Pearson correlation statistical analysis was done for detection of a probable significance between two different parameters. Results were considered significant if $\mathrm{p} \leq 0.05$.

\section{RESULTS}

Vitamin E reduces biomarkers of liver injury and oxidative stress induced by HFD but not TNF- $\alpha$. To determine whether vitamin $\mathrm{E}$ can inhibit HFD-induced up-regulation of liver injury enzymes (ALT and AST), and biomarkers of oxidative stress (MDA) and inflammation (TNF- $\alpha$ ) in our animal model of pre-diabetes, we measured the blood levels of ALT, AST, TNF- $\alpha$, and liver tissue levels of MDA in all rat groups. HFD caused augmentation of ALT (Fig. 1A), AST (Fig. 1B), MDA (Fig. 1C), and TNF- $\alpha$ (Fig. 1D), which were significantly $(\mathrm{p}<0.05)$ reduced with vitamin $\mathrm{E}$ treatment (HFD+Vit E) except TNF- $\alpha$. However, the level of these parameters (ALT, AST, and MDA) in the (HFD+Vit E) group were significantly elevated compared with the control.

Vitamin E partially protects hepatocyte ultrastructural damage induced by HFD. Using TEM technique, we investigated the effect of vitamin $\mathrm{E}$ treatment for 12 weeks on the protection against HFD-induced liver injury. Liver section obtained from the control group (Fig. 2A) showed a normal architecture of hepatocytes $(\mathrm{H})$ as demonstrated by a round centrally located nucleus $(\mathrm{N})$, crowded cytoplasm with organelles, particularly rough endoplasmic reticulum (RER) and mitochondria (M), and clear and intact plasma
A
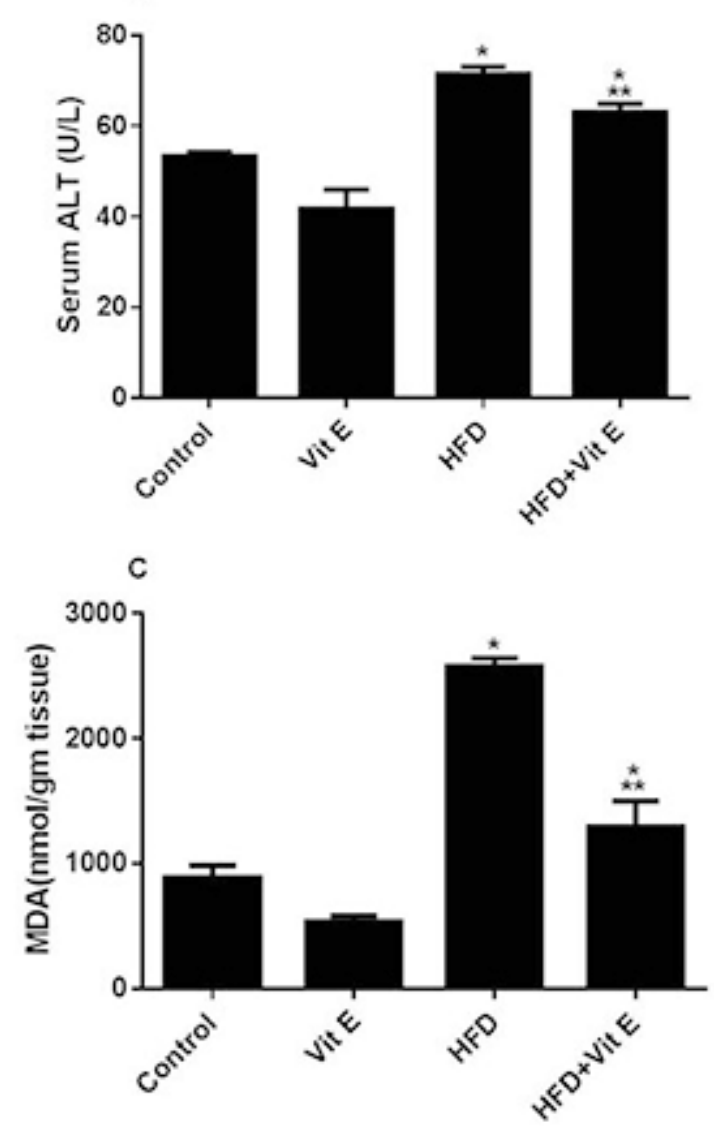
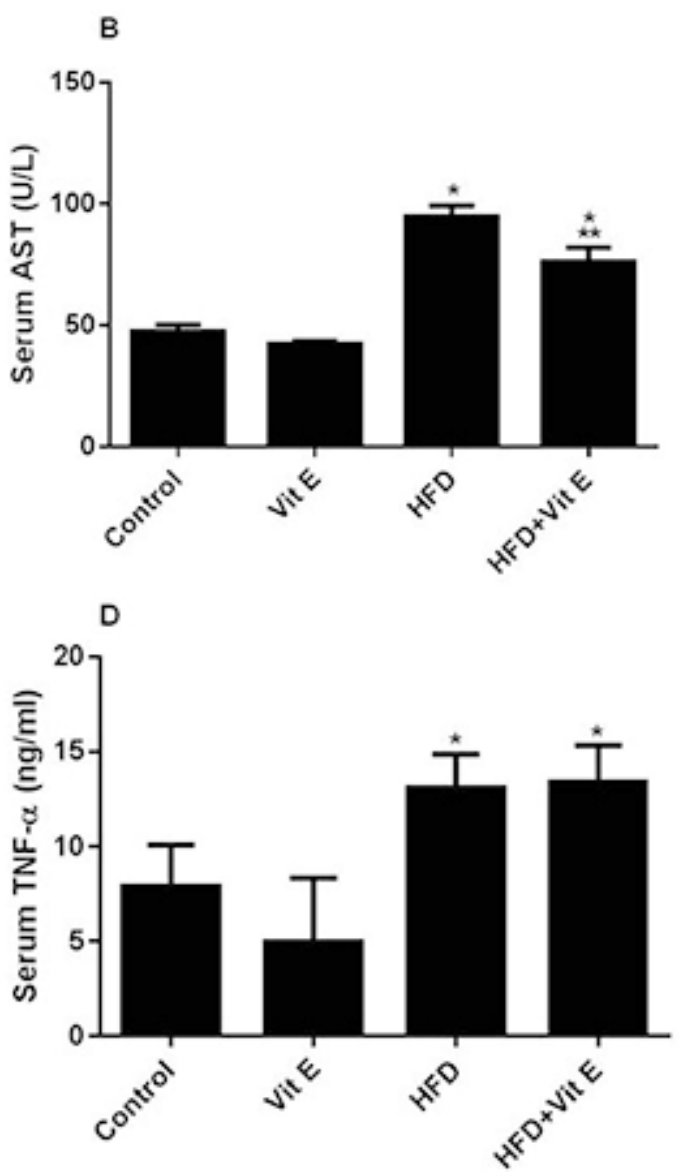

Fig. 1. Vitamin E reduces HFD-induced ALT, AST, and MDA, but not TNF- $\alpha$. Serum levels of ALT (A), AST (B), and TNF- $\alpha(\mathrm{D})$, and liver tissue levels of MDA (C) were measured in 4 groups of rats; Control, Control+vitamin E (Vit E), HFD, and HFD+vitamin E (HFD+Vit E) groups after 12 weeks. Results represent the mean $( \pm S D) ; n=6$ for each group. Experiments were performed in triplicate. ${ }^{*} \mathrm{p}<0.05$ versus control, ${ }^{*} \mathrm{p}<0.05$ versus HFD. 
membranes (arrows). TEM image represents liver sections of rats fed on HFD (Fig. 2B) displays variable mitochondrial swelling, dilation of endoplasmic reticulum, blebbing of plasma membranes, and cytoplasmic accumulations of lipid droplets and vacuoles. Treatment of the HFD rats with vitamin E (Fig. 2C) substantially but not completely protected the hepatocellular architecture, as demonstrated by a crowded cytoplasm with normal mitochondria and more intact plasma membranes compared to the HFD group. However, cytoplasmic vacuoles and irregular nuclear membrane still can be seen, which point to an on-going apoptosis.
Vitamin E protects against HFD-induced TG and LDL-C but does not affect TC and HDL-C levels modulated by HFD. To determine whether vitamin E can inhibit HFDinduced up-regulation of TG, TC, LDL-C, and augment HFD-induced down-regulation of HDL-C, we measured the blood levels of these lipids in all rat groups. HFD caused augmentation of TG (Fig. 3A), TC (Fig. 3B), LDL-C (Fig. 3C), and decreased the "good" cholesterol, HDL-C (Fig. 3D). Vitamin E significantly $(\mathrm{p}<0.05)$ lowered TG, and LDL-C, but did not affect TC and HDL-C levels (HFD+Vit E). The blood level of TG, and LDL-C in the (HFD+Vit E) group were significantly elevated compared with the control.
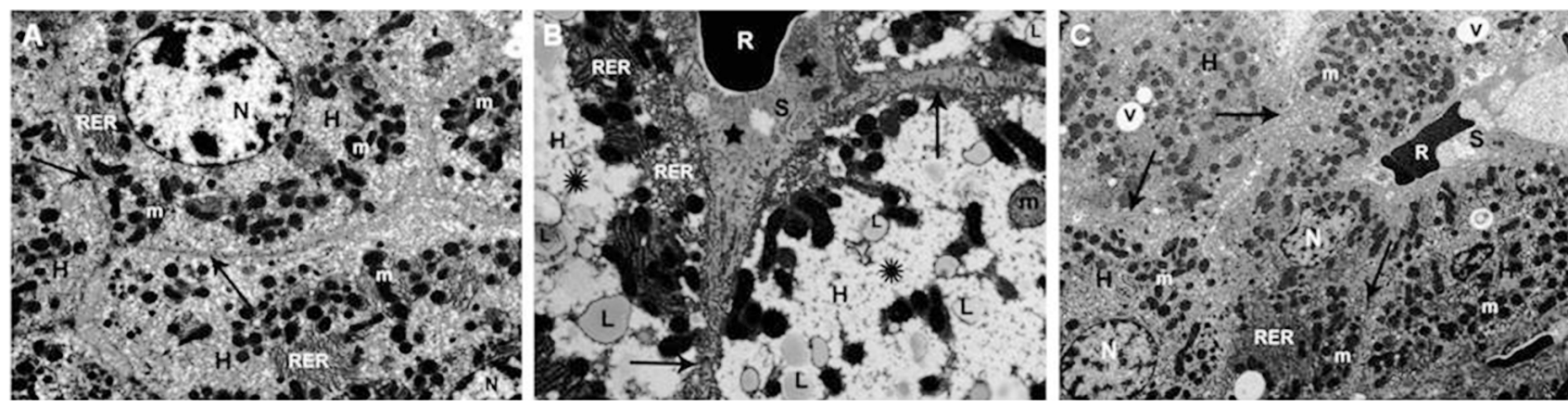

Fig. 2. Vitamin E ameliorates HFD-induced steatosis and liver injury. TEM images (5000x) of harvested tissues obtained after 12 weeks from the liver in different groups of rats used in the study; Control group (A), HFD fed group (B), and HFD+Vit E group (C). Note that arrows point to intercellular space between hepatocytes; asterisks, point to damaged cytoplasm of hepatocytes; stars, point to the mucus secretion within the lumen of blood sinusoid. Abbreviations: H, hepatocyte; N, nucleous; L, lipid droplets; m, mitochondria; RER, rough endoplasmic reticulum; V, vacuoles; S, blood sinusoid; R, erythrocyte.
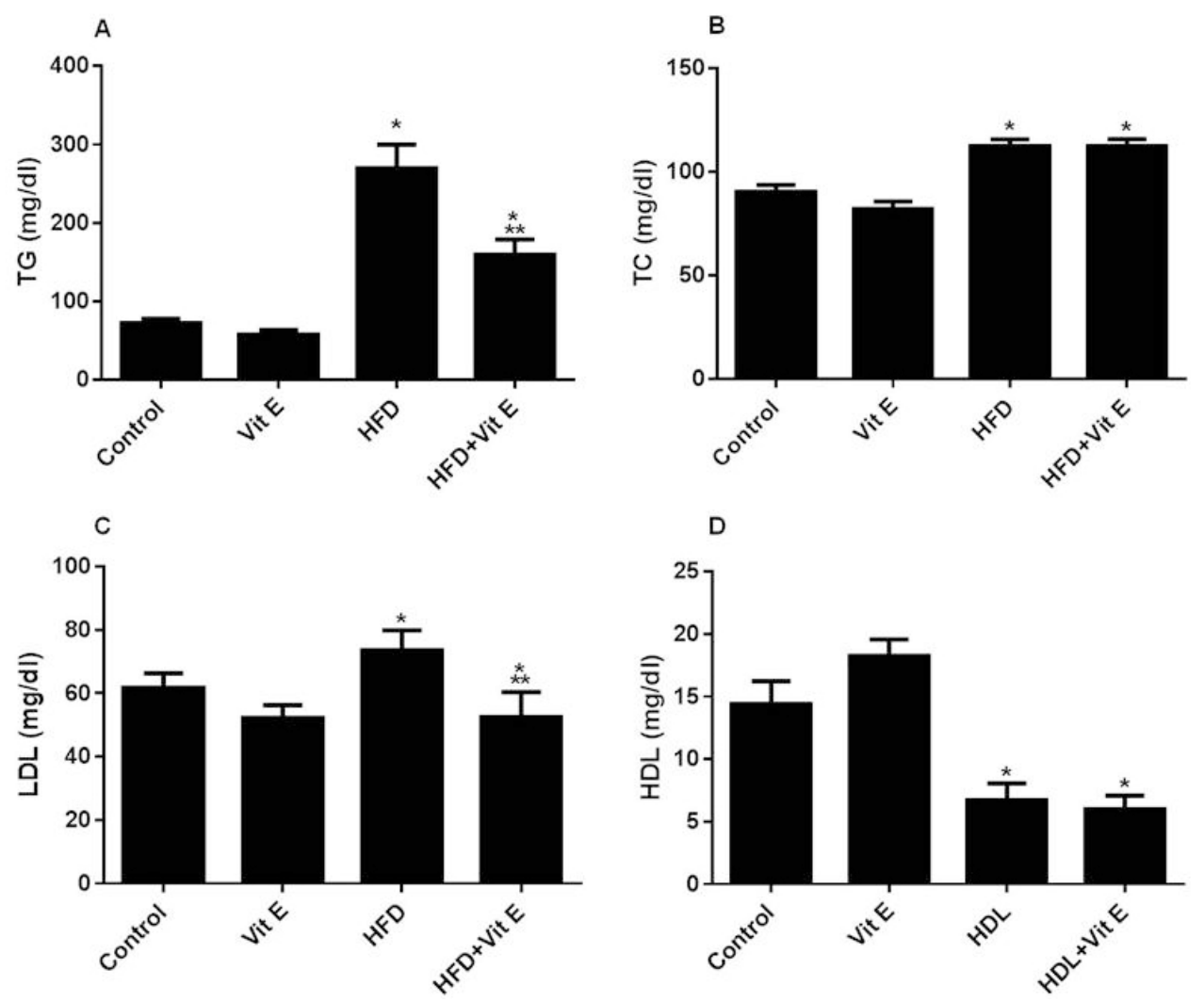

Fig. 3. Vitamin E modulates HFD-induced TG and LDL-C, but not TC and HDL-C. Serum levels of TG (A), TC (B), LDL-C (C), and HDL-C (D) were measured in 4 groups of rats; Control, Control+vitamin E (Vit E), HFD, and HFD+vitamin E (HFD+Vit E) groups after 12 weeks. Results represent the mean $( \pm S D) ; n=6$ for each group. Experiments were performed in triplicate. $* \mathrm{p}<0.05$ versus control, $* * p<0.05$ versus HFD. 


\section{DISCUSSION}

The main objective of our study was to investigate the potential protective effect of vitamin $\mathrm{E}$ to the hepatocyte ultrastructure against pre-diabetes-induced NAFLD in a rat model of the disease using TEM. In addition, a comparison was also made between the pathological and biochemical changes occurred in response to the disease and its potential treating drug, vitamin E. Therefore, we induced NAFLD in one group of rats using HFD, and the protective group was put on a HFD and vitamin E for 12 weeks before being sacrificed, leaving the model group of rats untreated for the same period. The main findings of our study were that (i) pre-diabetes induced hepatic steatosis and profound damage to hepatocyte ultrastructure; (ii) vitamin E substantially but not completely slowed down the progression of the disease in rats; and (iii) vitamin $\mathrm{E}$ significantly reduced certain biomarkers of liver injury and pre-diabetes but not all the investigated biomarkers. These conclusions are supported by the data indicating that HFD markedly increased liver injury enzymes (ALT and AST), oxidative stress biomarker (MDA), and lipids (TG and LDL-C), which were significantly reduced with vitamin $\mathrm{E}$ treatment (Figs. 1 and 3). In addition, vitamin E partially prevented damages occurred to liver cells after 12 weeks in rats fed on HFD (Fig. 2). However, vitamin $\mathrm{E}$ in our pre-diabetic animal model failed to significantly reduce TNF- $\alpha$ and TC, and to increase HDL-C (Figs. 1D, 3B and 3D). Furthermore, our finding of HFD significantly $(\mathrm{p}<0.05)$ increased the insulin resistance index (HOMA-IR), which was effectively $(\mathrm{p}<0.05)$ but not completely decreased by vitamin $\mathrm{E}$ (data not shown) further support our conclusion mentioned above.

Elevated blood levels of the liver enzymes ALT and AST are indicative of hepatic injury and a marker of the liver damage including hepatic steatosis (Chidambaram \& Carani Venkatraman, 2010; Gatineau et al., 2018). These reports are in agreement with our findings (Fig. 1), and the significant reduction in the levels of these enzymes upon treatment with vitamin E (Fig. 1) might account for the observed protection of the hepatocyte ultrastructure as indicated by a marked reduction in cytoplasmic fat droplets and a better architecture of the hepatocytes (Fig. 2). Similarly, our data that point to the elevation of MDA, TNF- $\alpha$, and dyslipidemia in pre-diabetes-induced NAFLD (Figs. 1 and 3 ) are in agreement with our recent reports (Al Humayed et al., 2017; Dallak, 2018; Dallak et al., 2018) and others (Noeman et al., 2011; Oh et al., 2014). However, conflicting data on the beneficial therapeutic use of vitamin $\mathrm{E}$ to treat NAFLD and NASH in humans were reported (Townsend \& Newsome, 2017). A 2 years clinical trial study on 53 NAFLD patients treated with vitamin E (600 IU/day) and vitamin C reported no effect on reducing ALT, steatosis, and inflammation (Nobili et al., 2008), which is in agreement with our data on inflammation, but not ALT and steatosis. Whereas, another clinical trial on 48 patients with the advanced NAFLD (NASH) for the same period (2 years) treated with vitamin E (400 IU twice a day) plus the drug that treats primary biliary cirrhosis, ursodeoxycholic acid also showed no effect on inflammation, but reduced both ALT and steatosis (Dufour et al., 2006).

Collectively, this study demonstrates that feeding rats with a HFD diet for 12 weeks resulted in hepatic steatosis that damaged the ultrastructure of hepatocytes and released liver injury enzyme into the circulation, possibly via augmentation of lipids and oxidative stress biomarkers. Vitamin E was partially effective in inhibiting liver dysfunction.

\section{ACKNOWLEDGEMENTS}

The authors would like to acknowledge the input and help of Professor Bahjat Al-Ani from the Physiology Department, College of Medicine, King Khalid University, Abha, Saudi Arabia.

ELLATIF, M. A.; EL KARIB, A.; DALLAK, M.; EID, R. A.; AL-ANI, R. \& HAIDARA, M. A. La vitamina E protege contra el daño ultraestructural de los hepatocitos inducido por la dieta alta en grasas en un modelo de pre-diabetes en ratas. Int. J. Morphol., 36(4):1350-1355, 2018.

RESUMEN: El objetivo de este estudio fue investigar el posible efecto protector de la administración de suplementos de vitamina E contra las alteraciones ultraestructurales de los hepatocitos inducidas por una dieta rica en grasas (DRG) en un modelo de prediabetes en ratas. Antes de ser sacrificadas las ratas fueron alimentadas con DRG (grupo modelo) o un alimento estándar de laboratorio (grupo control) durante 12 semanas. El grupo protector se alimentó con una DRG y comenzó el tratamiento con vitamina $\mathrm{E}$ ( $100 \mathrm{mg} / \mathrm{kg} /$ día, i.p) desde el día 1 hasta sacrificarlo en la semana 12. Los tejidos hepáticos recolectados se examinaron mediante microscopía electrónica de transmisión (MET) y se tomaron muestras de sangre y se analizaron los biomarcadores de daño hepático y prediabetes. Las imágenes de MET mostraron que el DRG indujo cambios patológicos profundos en la ultraestructura de los hepatocitos, como lo demuestran los hepatocitos degenerados con citoplasma dañado e hinchazón mitocondrial, dilatación del retículo endoplasmático, formación de ampollas en las membranas plasmáticas y acumulaciones citoplásmicas de gotas de lípidos y vacuolas, los que fueron sustancialmente protegidas con vitamina E. Además, DRG aumentó significativamente $(\mathrm{p}<0,05)$ los biomarcadores de daño hepático y prediabetes como alanina aminotransferasa (ALT), aspartato aminotransferasa (AST), factor 
de necrosis tumoral alfa (TNF- $\alpha$ ), malondialdehído (MDA), colesterol total (CT), triglicéridos (TG) y lipoproteína de colesterol de baja densidad (LDL-C), la cual se redujo significativamente (p $<0,05)$ con vitamina E, excepto TNF- $\alpha$ y CT. Ninguno de estos biomarcadores se redujo al nivel de control por la vitamina E. Concluimos que la vitamina $\mathrm{E}$ es un agente protector parcial contra la lesión hepática inducida por DRG y la prediabetes.

PALABRAS CLAVE: Ultraestructura de hepatocitos; Pre-diabetes; Esteatosis hepática; Vitamina E; Modelo animal.

\section{REFERENCES}

Al Humayed, S.; Eid R. A.; Shatoor, A. S.; Haidara, M. A.; Zaki, M. S. A. \& Al-Ani, B. Differential therapeutic effects of crataegus aronia and simvastatin on the hepatocyte ultrastructure in hepatic steatosis. Int. J. Morphol., 35(2):578-83, 2017.

Angulo, P. \& Lindor, K. D. Non-alcoholic fatty liver disease. $J$. Gastroenterol. Hepatol., 17 Suppl.:S186-90, 2002.

Benlhabib, E.; Baker, J. I.; Keyler, D. E. \& Singh, A. K. Effects of purified puerarin on voluntary alcohol intake and alcohol withdrawal symptoms in $\mathrm{P}$ rats receiving free access to water and alcohol. J. Med. Food, 7(2):180-6, 2004

Brockes, C.; Buchli, C.; Locher, R.; Koch, J. \& Vetter, W. Vitamin E prevents extensive lipid peroxidation in patients with hypertension. Br. J. Biomed. Sci., 60(1):5-8, 2003.

Byrne, C. D. \& Targher, G. NAFLD: a multisystem disease. J. Hepatol., 62(1 Suppl.):S47-64, 2015.

Chalasani, N.; Younossi, Z.; Lavine, J. E.; Diehl, A. M.; Brunt, E. M.; Cusi, K.; Charlton, M. \& Sanyal, A. J. The diagnosis and management of non-alcoholic fatty liver disease: practice Guideline by the American Association for the Study of Liver Diseases, American College of Gastroenterology, and the American Gastroenterological Association. Hepatology, 55(6):2005-23, 2012.

Chidambaram, J. \& Carani Venkatraman, A. Cissus quadrangularis stem alleviates insulin resistance, oxidative injury and fatty liver disease in rats fed high fat plus fructose diet. Food Chem. Toxicol., 48(8-9):20219,2010.

Choi, S. \& Diehl, A. M. Role of inflammation in nonalcoholic steatohepatitis. Curr. Opin. Gastroenterol., 21(6):702-7, 2005.

Dallak, M. A. Suppression of high fat diet-induced liver cell injury by swim exercise. Int. J. Morphol., 36(1):327-32, 2018.

Dallak, M. A.; Bin-Jaliah, I.; Albawardi, A.; Haidara, M. A.; Sakr, H. F.; Eid, R. A.; Hassan, W. N. \& Al-Ani, B. Swim exercise training ameliorates hepatocyte ultrastructural alterations in rats fed on a high fat and sugar diet. Ultrastruct. Pathol., 42(2):155-61, 2018.

de Alwis, N. M. \& Day, C. P. Non-alcoholic fatty liver disease: the mist gradually clears. J. Hepatol., 48 Suppl. 1:S104-12, 2008.

Dufour, J. F.; Oneta, C. M.; Gonvers, J. J.; Bihl, F.; Cerny, A.; Cereda, J. M.; Zala, J. F.; Helbling, B.; Steuerwald, M.; Zimmermann, A. \& Swiss Association for the Study of the Liver. Randomized placebo-controlled trial of ursodeoxycholic acid with vitamin e in nonalcoholic steatohepatitis. Clin. Gastroenterol. Hepatol., 4(12):1537-43, 2006.

Eckel, R. H.; Grundy, S. M. \& Zimmet, P. Z. The metabolic syndrome. Lancet, 365(9468):1415-28, 2005.

Gatineau, E.; Capel, F.; Dardevet, D.; David, J.; Pouyet, C.; Polakof, S. \& Mosoni, L. Effect of high chronic intake of sucrose on liver metabolism in aging rats. Modulation by rutin and micronutrients. J. Physiol. Biochem., 2018. DOI: 10.1007/s13105-018-0628-y [Epub ahead of print]

Grattagliano, I.; Palmieri, V. O.; Portincasa, P.; Moschetta, A. \& Palasciano,
G. Oxidative stress-induced risk factors associated with the metabolic syndrome: a unifying hypothesis. J. Nutr. Biochem., 19(8):491-504, 2008.

Kopelman, P. G. Obesity as a medical problem. Nature, 404(6778):63543, 2000.

Lee, S. J.; Kim, S. Y. \& Min, H. Effects of vitamin C and E supplementation on oxidative stress and liver toxicity in rats fed a low-fat ethanol diet. Nutr. Res. Pract., 7(2):109-14, 2013.

Lustig, R. H.; Schmidt, L. A. \& Brindis, C. D. Public health: The toxic truth about sugar. Nature, 482(7383):27-9, 2012

Nobili, V.; Manco, M.; Devito, R.; Di Ciommo, V.; Comparcola, D.; Sartorelli, M. R.; Piemonte, F.; Marcellini, M. \& Angulo, P. Lifestyle intervention and antioxidant therapy in children with nonalcoholic fatty liver disease: a randomized, controlled trial. Hepatology, 48(1):119$28,2008$.

Noeman, S. A.; Hamooda, H. E. \& Baalash, A. A. Biochemical study of oxidative stress markers in the liver, kidney and heart of high fat diet induced obesity in rats. Diabetol. Metab. Syndr., 3(1):17, 2011.

Oh, J.; Lee, S. R.; Hwang, K. T. \& Ji, G. E. The anti-obesity effects of the dietary combination of fermented red ginseng with levan in high fat diet mouse model. Phytother. Res., 28(4):617-22, 2014.

Ohkawa, H.; Ohishi, N. \& Yagi, K. Assay for lipid peroxides in animal tissues by thiobarbituric acid reaction. Anal. Biochem., 95(2):351-8, 1979.

Paschos, P. \& Paletas, K. Non alcoholic fatty liver disease and metabolic syndrome. Hippokratia, 13(1):9-19, 2009.

Said, A. Non-alcoholic fatty liver disease and liver transplantation: outcomes and advances. World J. Gastroenterol., 19(48):9146-55, 2013.

Townsend, S. A. \& Newsome, P. N. Review article: new treatments in nonalcoholic fatty liver disease. Aliment. Pharmacol. Ther, 46(5):494-507, 2017.

Zezos, P. \& Renner, E. L. Liver transplantation and non-alcoholic fatty liver disease. World J. Gastroenterol., 20(42):15532-8, 2014.

\author{
Corresponding author: \\ Professor Mohamed A Haidara \\ Department of Physiology \\ College of Medicine \\ King Khalid University \\ Abha 61421 \\ SAUDI ARABIA
}

Email: haidaram@hotmail.com

Received: 26-04-2018

Accepted: $26-07-2018$ 